\section{Ethics and aging: focus on living will for patients with dementia}

\author{
Alberto Sardella, Laura Vernuccio, \\ Floriana Cocita, Florenza Inzerillo, \\ Ligia J. Dominguez, Mario Barbagallo \\ Geriatrics and Long Term Care Unit, \\ University of Palermo, Italy
}

\begin{abstract}
Today dementia certainly represents a public health priority with a huge global impact on wordwide population. However, clinical and social issues related to dementia have long been marginalized. The actual high prevalence of dementias requires also to face issues from a bioethical perspective, regarding how to deal with demented patient's disposition.

There are currently no specific guidelines on the national territory regarding whether to draw up a living will by a patient with dementia, neither about the informative role of physicians during the progressive story of the disease.
\end{abstract}

\section{Introduction}

In 2015 more than 46 million people were affected by dementia. This amount is estimated to almost double every 20 years, increasing to 131.5 million by $2050 .{ }^{1}$ Alzheimer's disease (AD) is the most common form of dementia and it possibly contributes to $60-70 \%$ of cases. In 2006 the worldwide prevalence of $\mathrm{AD}$ was indicated in 26.6 million. It was also estimated that this number would quadruple by 2050 , so that 1 out 85 subjects would be living with the disease. ${ }^{2}$

These numbers well point out how today dementia certainly represents a public health priority with a huge global impact on wordwide population.

However, clinical and social issues related to dementia - especially to AD have long been marginalized by the international scientific community and society in general. Dementia was often configured as integral part of aging or rather a taboo subject. Moreover, the absence of a cure, net of symptomatic therapies currently in use, has certainly played a decisive role, which has led to simply conceive dementia as an inescapable destiny. We should not forget that dementia, by definition, ${ }^{3}$ is a syndrome caused by a number of progressive illnesses that affects on different levels cognitive functions, behavior and the ability to independently perform everyday activities.

In this context, the risk is to receive a diagnosis of dementia only at an advanced stage, often when even behavioral and psychological symptoms are already exacerbated and the burden both for patient and caregiver has increased.

The actual high prevalence of dementias (especially $\mathrm{AD}$ ) requires to face with new problems and to decide as well on issues for which there are no immediate answers. It is especially difficult for family members and caregivers who often have to make these decisions on behalf of the patient. As a matter of fact, subjects with dementia, compared for example to patients affected by different medical conditions, likely have little space to express their will, due to the progressive cognitive impairment which makes them less and less aware of their pathological status.

\section{Discussion}

From a bioethical perspective, selfdetermination clearly represents a cardinal principle in the doctor/patient relationship. The question of self-determination in subjects with dementia is actually an area of debate. ${ }^{4}$ While, according to the law, the right to self-determination of every adult citizen must be respected, on the other side cognitive disabilities progressively affect their capacity to make decisions. ${ }^{5}$

A widely accepted definition of decision-making capacity ${ }^{6}$ is based on the following strongholds. The patient should: i) understand relevant information on the treatment, including the risks and the benefits; ii) be able to assess the situation and its consequences; iii) be able to evaluate the different therapeutic alternatives; iv) know how to communicate a choice.

Generally to evaluate these skills two different approaches can be taken in account: to create ad hoc tools (questionnaires and interviews) or to adapt neuropsychological test batteries normally used in the assessment of cognitive impairment. ${ }^{7} \mathrm{~A}$ proper evaluation, indeed, should not leave aside those cognitive functions known as executive functions, involved in several aspects of daily life. Neuropsychological tests of complex abilities such as attention, memory, frontal functions, language and visuospatial abilities should be incorporated into capacity assessments.

Moreover a deep psychopathological assessment it is also crucial to exclude the
Correspondence: Alberto Sardella, Geriatrics and Long Term Care Unit, University of Palermo, Italy.

E-mail: albi.sardella@gmail.com

Key words: Living will; dementia; Alzheimer geriatrics.

Received for publication: 24 May 2017. Accepted for publication: 3 July 2017.

This work is licensed under a Creative Commons Attribution-NonCommercial 4.0 International License (CC BY-NC 4.0).

(C) Copyright A. Sardella et al., 2017

Licensee PAGEPress, Italy

Geriatric Care 2017: 3:6815

doi:10.4081/gc.2017.6815

presence of a psychiatric condition or personality disorder which could affect subject's self determination.

In the precise order to respect the patient's right to self-determination, scientific community and international politics have recently begun to discuss the proposal for a living will even to subjects with dementia. This will basically configures the possibility to decide before being no longer able to do so and its use is well known especially in cases of euthanasia.

In this context, living will appears to be one of the most suitable instruments to ensure greater respect for the will of a demented patient along his disease's progression. However, as previously pointed, dementia is a story that is written over many years (on average, ten) during which is gradually established an inability to make even the most basic decisions of daily life.

It is therefore necessary to evaluate when a living will should be proposed to a patient who has been taken in care for cognitive impairment (Figure 1). It could be a proper choice by the physician to discuss this opportunity early in the disease, when the subject is still able to understand and perhaps make plans.

It should also be remembered that precisely in the early stages of the disease the patient appears to be more vulnerable, due to several changes he/she is experiencing which involve his/her cognition and generate a real psychological burden. It would be strongly recommended a specific work on the disease awareness in order to make wise and weighted decisions about the future. In this context could play a key role not only the quality of the doctor/patient relationship, but also a correct diagnosis disclosure by the physician, the trust and support from his family and eventually a psychotherapeu- 
tic process aimed to the acceptance of the disease.

Another point regards the topics on which the patients would express their premature will. During the disease decisions to be taken are many, diluted over time, having a strong influence on quality of life. Not to mention the emotional impact of patients who might no longer be able to modify their will due to advancing cognitive decline.

To at least partially overcome these problems, the appointment of a health care proxy could be a useful proposal. This person would be chosen by the patient and should be well informed about his/her med- ical history. Generally the one pointed as proxy is a member of family or anyway a person in whom the patient places the utmost confidence in order to interpret his/her will when he/her will no longer be able to fulfill it. This health care figure should be proposed not simply when a diagnosis of dementia is made by the physician, but rather after mental capacity of the patient has been fully assessed. In fact, while on the one hand it is true that people with dementia have a higher risk of impaired abilities than non-affected, on the other hand a diagnosis of dementia by itself does not necessarily mean that a person has

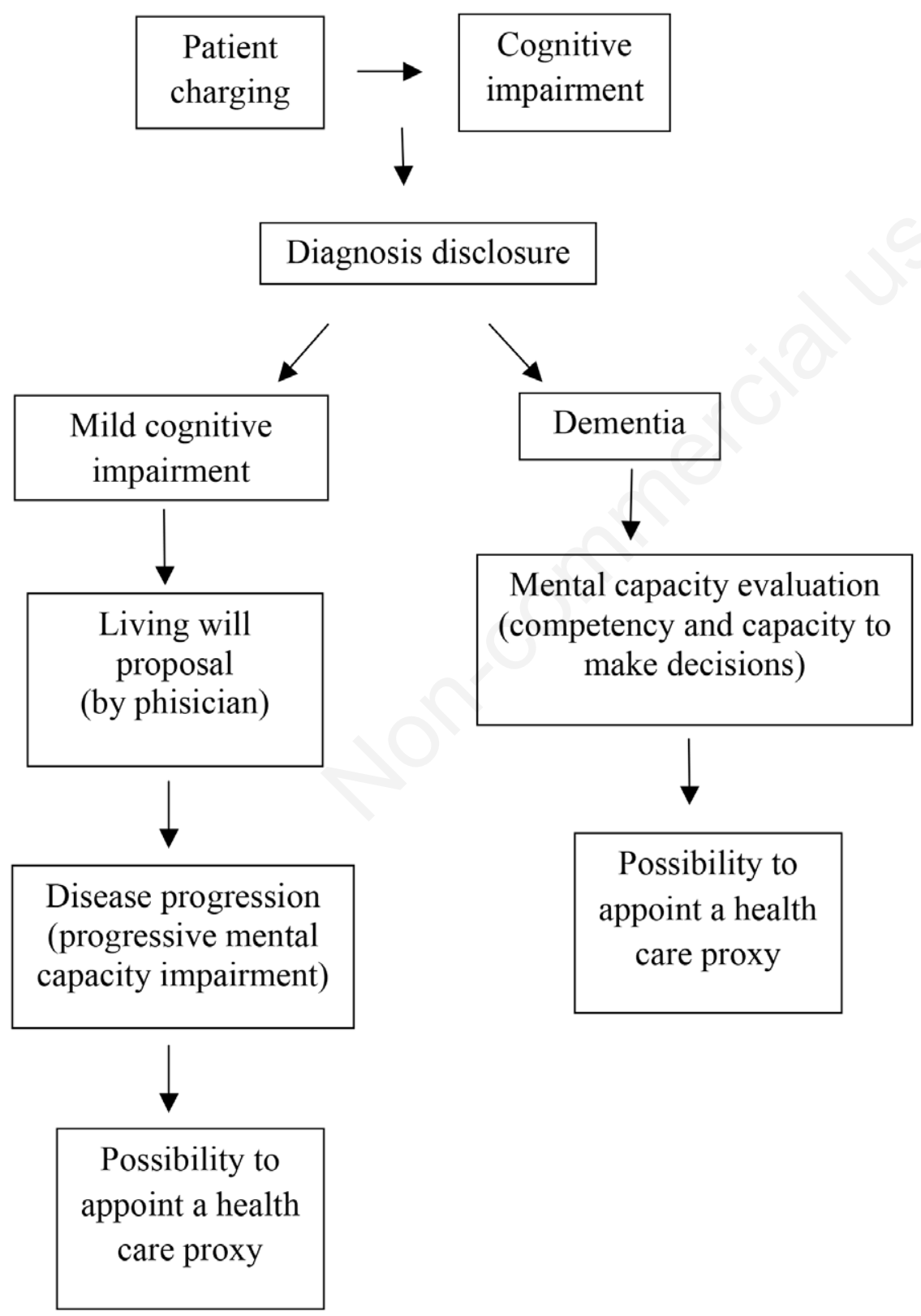

Figure 1. Living will and clinical practice. lost his capacity to self-determination. ${ }^{8}$

The questions which have been described however clash with several sociopolitic realities not yet ready to meet with these needs. Italy, for instance, is a sensitive country though divided between secularism and religion. A recent national report ${ }^{9}$ pointed a prevalence of almost one million individuals affected by dementia. The Italian Government still tries to reach the solution of these complex issues. However, the right to health ${ }^{10}$ enshrined in the Constitution lends itself to several interpretations.

There are currently no specific guidelines on the national territory regarding whether to draw up a living will by a patient with dementia, neither about the informative role of physicians during the progressive story of the disease.

\section{Conclusions}

In conclusion, for an adequate health care planning, even in dementia, it is our opinion that the writing of a living will should be proposed to the patients in the early days of their medical care. The need to improve the quality of life of patients with dementia goes also hand in hand with recent scientific findings ${ }^{11,12}$ showing that subtle changes or preclinical disabilities may affect daily autonomy even in presence of a mild cognitive decline.

In this context, shared bioethical guidelines are necessary ${ }^{13}$ so that physicians who deal with patients affected by dementia should discuss every implication as soon as possible after a diagnosis is reached.

\section{References}

1. Alzheimer's Disease International. Word Alzheimer Report 2015: The Global Impact of Dementia. Available from: https://www.alz.co.uk/research/ world-report-2015

2. Brookmeyer R, Johnson E, ZieglerGraham K, Arrighi HM. Forecasting the global burden of Alzheimer's disease. Alzheimer Dementia 2007;3:186-91.

3. American Psychiatric Association. Diagnostic and Statistical Manual, 4th ed. Washington, DC: APA Press; 1994.

4. German Ethics Council. Dementia and self-determination. Berlin: Deutscher Ethikrat; 2013. Available from: http://www.ethikrat.org/files/opiniondementia-and-self-determination.pdf

5. Osterholm JH, Taghizadeh Larsson A, Olaison A. Handling the dilemma of 
self-determination and dementia: a study of case managers' discursive strategies in assessment meetings. J Gerontol Soc Work 2015;58:613-36.

6. American Psychiatric Association. Guideline for assessing the decisionmaking capacities of potential research subjects with cognitive impairment. Am J Psychiatry 1998;155:1649-50.

7. Sullivan K. Neuropsychological assessment of mental capacity. Neuropsychol Rev 2004;14:131-42.

8. Kim SYH, Karlawish JHT, Caine ED. Current state of research on decision- making competence of cognitively impaired elderly persons. Am J Geriatr Psychiatry 2002;10:151-65.

9. ISTAT (Italian National Institute of Statistics). Rapporto annuale 2014 - La situazione del Paese - Capitolo 4: Tendenze demografiche e trasformazioni sociali: nuove sfide per il sistema di welfare. Available from: http://www.istat.it/it/archivio/120991

10. Costituzione della Repubblica Italiana. Art. 32. G.U. n. 298 del 27/12/1947.

11. Perneczky R, Pohl C, Sorg C, et al. Impairment of activities of daily living requiring memory or complex reasoning as part of the MCI syndrome. Int J Geriatr Psych 2006;21:158-62.

12. Rodakowky J, Skidmore ER, Reynolds $\mathrm{CF}$, et al. Can performance of daily activities discriminate between older adults with normal cognitive function and those with mild cognitive impairment?. J Am Geriatr Soc 2014;62:1347-52.

13. Burlà $\mathrm{C}$, Rego G. Alzheimer, dementia and the living will: a proposal. Med Health Care Philos 2014;17:389-95. 